\title{
Chapter 13 Engaging with STEM students: successes and challenges in course design
}

Leigh Ellen Potter and Alexandra Thompson

\begin{abstract}
In this chapter, we will describe the approach taken to design a new first year core course for a multidisciplinary STEM student cohort. This cohort presented challenges in terms of size, location, interest, understanding, and existing knowledge. We drew on the lessons learned from a previous redesign project for a course that shared many of these attributes to develop a course structure and approach to address these challenges. The design of the material, supporting technology, assessment, and class activities were structured to both support student learning and engage students in the learning process through a blended classroom approach and an active learning strategy. We utilised tools within the Blackboard learning management system together with the PebblePad platform for interaction to blend course elements. We followed a formal evaluation process, and identified that the module and workshop structure implemented in this design were successful in supporting student learning of complex material. We observed that the quality of student work generally improved across the teaching period. Evaluations identified issues with the use of the PebblePad platform in terms of limitations for collaborative work, and restrictions for document preparation. We have found that it is difficult to consistently engage with all students, and we will expand our approach to incorporate digital responses to questions and surveys with improved ability for the students to capture their own learning locally. Potential platforms to support these activities are the university native polling tool jPoll, the PebblePad platform, and the Echo360 Active Learning platform.
\end{abstract}

\section{Introduction}

In 2015, the School of Information and Communication Technology (ICT) embarked on a major process of updating and redeveloping its undergraduate and Masters degree programs. The school identified a need to revise the degree structures and course offerings with a focus on empowering graduates with knowledge and skills for the future, supporting student creativity and innovation, and creating world-leading educational content and experiences for students from all walks of life to provide them with the foundation and skills to become leaders in their fields and communities. This resulted in the development of an entirely new program of courses tailored to meet the evolving technology environment and our changing student cohorts. One of the new courses scheduled to be taught in 2016 was Human Computer Interaction ( $\mathrm{HCl}$ ), a foundation course that presented a unique challenge for course design due to its cross-disciplinary, multi-campus, large first-year cohort.

In developing the design for the new $\mathrm{HCl}$ course, we needed to ensure that the course structure was based on a practical approach that would work for technology students, who benefit from an active and applied approach to course material (Freeman et al., 2014; Kennedy \& Odell, 2014; Potter, 2018). We drew on work from a previous project conducted using participatory design with student teams to redevelop an existing project management course. The lessons learned from this process provided an architecture for the blended learning design for the $\mathrm{HCl}$ course.

The nature of the $\mathrm{HCl}$ course as a foundational unit for the new degree presented an additional challenge - how to make the course engaging and interactive, supporting students in building knowledge to inform and guide the rest of their degree. The choice of 
technology to support the implementation of the course was critical. An opportunity arose to trial a new technology, PebblePad, as a central interactive platform that was linked within a standard Blackboard course site.

This chapter will describe how the lessons of the project management redevelopment informed the design and development of the blended learning approach for $\mathrm{HCl}$ using PebblePad as a support platform. We will describe the structure of the $\mathrm{HCl}$ course, and the successes and challenges of the course design and deployment process. The evaluation of the course will be outlined, and our future directions will be described.

\section{Background}

The School of ICT offers a range of undergraduate and postgraduate degree programs including the Bachelors of Information Technology, Applied Information Technology, Computer Science, and Intelligent Digital Technologies; Masters of Enterprise Architecture, Information Systems and IT Management, and Information Technology; and graduate certificates and diplomas. The school supports approximately 1400 students across three campuses. The undergraduate cohort share key characteristics that inform the strategies used for course design: $90 \%$ of undergraduate students have a low to medium socioeconomic status, nearly half are first in family students, $90 \%$ are under the age of 25 , and $83 \%$ are domestic students.

In this paper we will discuss the approach taken to design and develop the $\mathrm{HCl}$ course, which was introduced as a new and original course in Semester 2, 2016. It was a large firstyear undergraduate core course with a 2016 enrolment of 412 students from the Bachelors of Information Technology, Computer Science, Creative and Interactive Media (co-taught with the Queensland College of Art), Intelligent Digital Technologies, and Software Engineering programs, taught across three campuses. As a core course for all ICT degree programs, the student population for $\mathrm{HCl}$ was diverse, and the course must be able to meet the needs of students with a broad range of subject interests and background knowledge. The $\mathrm{HCl}$ course was introduced as part of the new program redesign, and had not been taught as part of the previous programs.

\subsection{Prior Work - a Redesign Project for an Existing Course}

As a new course, we had no prior course content, structure, or delivery to support the development of $\mathrm{HCl}$. Instead, we looked at the delivery of an existing course: Project Management. As part of an earlier project, we conducted a major redevelopment of this course, and it was chosen as the course design model based on the characteristics it shared with $\mathrm{HCl}$, and on the success of the redesign project. As with $\mathrm{HCl}$, Project Management was core and compulsory across all degrees offered by the School of ICT. This was a large course with a total enrolment of approximately 350 students across two on-campus offerings and an online offering, run at undergraduate level and with some additional material at Masters level. The students taking the course were from diverse academic disciplines including software engineering, information systems, computer science, and multimedia, with a range of academic abilities, prior knowledge, and experiences. For many students intrinsic motivation to engage with the course was low. The course was challenged by poor student satisfaction and academic outcomes: course evaluations were low, student feedback in classes was negative, students were disengaged and struggled with many of the concepts, few students received high grades, and the failure rate in the course was high. Student feedback indicated that they found the course material to be dry, difficult, and lacking in relevance, and the course structure to be complex and unclear.

The Project Management course was taught in blended learning mode, with all theoretical material delivered online in weekly topics, and face-to-face contact provided through a weekly two-hour workshop (Shaidullin, Safiullin, Gafurov, \& Safiullin, 2014; Wang, Han, \& Yang, 2015). Our goals for the redevelopment project were to engage students in the course and support learning, improve the course structure, identify and support threshold concepts, 
support struggling students while still challenging high achieving students, and create an authentic experience that would reflect industry practice, build employability for students, and prepare them for their capstone courses in their final year. The approach selected to address this was to actively involve the students in the redevelopment process using the Participatory Design (PD) usability technique to ensure their needs were met.

PD means designing and developing technology in partnership with people, based on the philosophy that the people who will use a technology should be actively involved in the design and development of that technology (Simonsen \& Robertson, 2013). Within education, a PD partnership can be defined as a "collaborative, reciprocal process through which all participants have the opportunity to contribute equally, although not necessarily in the same ways, to curricular or pedagogical conceptualization, decision-making, implementation, investigation, or analysis" (Cook-Sather, Bovill, \& Felten, 2014, pp. 6-7). Productive partnerships between academics and students can enhance both teaching and learning experiences (Felten, Bovill, \& Cook-Sather, 2014).

The Project Management redesign project consisted of three PD cycles working with STEM students who had previously completed the Project Management course. These cycles explored the course characteristics that hindered student progression and identified a set of specific issues, including: aspects of the course content that created confusion, additional required support, threshold concepts, structural issues, issues with the site used to host the course material, and presentation of the theoretical elements. Based on identified issues, a range of revisions and technology interventions were iteratively developed during the three PD cycles to improve the course.

\subsection{Outcomes from the Project Management Redevelopment Project}

The Project Management redesign project delivered broad changes to both the course structure and the course material. We generated a set of course specific solutions, including a redeveloped course structure, scaffolded course material and assessment, a redeveloped course site, additional course material, technology applications to explain complex theory and tools, video interviews, and short animated video lecturettes. While many of the outcomes were specific to the course, several broader outcomes were observed that are more generally applicable to course development and redesign. Working collaboratively with the students resulted in a course structure that they found engaging and that supported their learning, consisting of the progressive presentation of course material. This material was structured as a series of modules that built project management knowledge. Each module included an introductory overview and a set of learning outcomes, a module book summarising the theoretical material, links to additional supporting readings, a workshop activity, a link to the discussion board for the module, an overview of what the students should be working on for their assessment, and a set of reflective questions. The course site incorporated a weekly schedule to support easy access to the material, providing students with a central map illustrating course elements against study weeks and assessment deliverables.

Each workshop class commenced with a group discussion of the topic which allowed instructors to gauge student understanding of the material and to correct any errors in that understanding within the class. This was followed by a practical exercise, where students were required to apply the module material to a specific project management situation. Each workshop finished with an assessment exercise. Using this approach, student learning was supported from theory through to application.

The students' primary assessment was a team-based activity completing a workbook of project management documents addressing a real project Call for Tender. The exercises they completed within the workshops directly contributed to their completion of the workbook assessment, and the assessment exercise within the workshop allowed each team to meet with the workshop instructor for in-person feedback.

This revised course structure resulted in improvements to both student satisfaction and student learning outcomes: student satisfaction in the course rose from 2.7 (out of 5) at the 
start of the project to 4.5 at the end of the project, and academic outcomes included improved results as indicated by student participation in activities, improved assessment marks, and a reduced course failure rate (dropping to under $10 \%$ of students failing, down from a start point of 24\%). The lessons learned from the success of this project appeared appropriate to inform the development of Human Computer Interaction.

\subsection{The Challenge: Transitioning from Project Management to $\mathrm{HCl}$}

Both Project Management and $\mathrm{HCl}$ were taught to a large student cohort across multiple campuses, necessitating the use of a common course site for consistency of content delivery and student experience. The courses shared the core course requirement, meaning that students take the course as a necessity rather than by choice. The size and nature of the cross-disciplinary student cohort produced diverse student expectations and personal career goals and study requirements. Both courses required specific and focused content in an area of unfamiliarity for many students, potentially in an area that students may not perceive as directly related to their own goals or interests. An approach with a focus on both clarity and engagement was required. These shared attributes supported the use of the successful framework developed for Project Management within the $\mathrm{HCl}$ course.

The transition required consideration of the specific challenges involved with the $\mathrm{HCl}$ course. The course was new and untried, providing no prior student experience of the course to draw on, and no option for student participation in a participatory design round. The course audience are predominantly first-year students, with some students in their first semester of university, giving them less experience with tertiary education standards and a lower likelihood of knowing other students or of having an existing student support network. An approach was required that would support tailoring of course development based on the lessons learned from the previous course redesign project.

\section{Approach}

Course design is an ongoing process, allowing progressive improvements based on experience and feedback (Moreton \& Conklin, 2015). The student experience during teaching is monitored based on student feedback, and at the end of each course offering, a full evaluation and review process is undertaken.

This process of dynamic course design supports the changing needs of both the information technology industry, and the students themselves. Hardware capabilities and software application are in a state of constant change and evolution, and as an IT course the $\mathrm{HCl}$ content must keep pace with a changing industry. The high school curriculum is also changing, and a new focus on technology skill acquisition in schools is prevalent. This translates to the arrival of first-year students with a broader knowledge base. The course design and content must keep pace with this prior knowledge if the course is to remain engaging and relevant for students.

A staged design approach was taken for the development of the new $\mathrm{HCl}$ course, commencing with generation of desired course learning outcomes and core course topics based on curriculum requirements generated by the Association of Computing Machinery (The Joint Task Force on Computing Curricula, 2013; Topi et al., 2010) for $\mathrm{HCl}$ and on recommendations from the Australian Computer Society. We used Koper's (2005) approach to learning design by seeking to answer the questions of what support students would need to learn the $\mathrm{HCl}$ concepts, what assessment would measure the learning process, and what we would need to "make learning and support as effective, efficient, attractive and accessible as possible for everyone involved in the process" (p. 3). We applied the lessons learned from the Project Management redesign project to inform the answers to these questions, using this experience to generate the structure of the $\mathrm{HCl}$ course and the scaffolding of the core concepts. We generated templates for exercises and assessment together with hints and explanatory documents to support learning. We developed teambased activities to foster a collaborative learning approach, and designed assessment around authentic tasks to effectively measure the learning process. Our approach to design 
for this course was iterative, with evaluation activities conducted both during the course and on course completion. This informed progressive course revisions and improvements.

A core aspect of course design was the selection of appropriate technology for course delivery in order to support a coherent course design appropriately integrating face to face teaching with online resources (Garrison \& Vaughan, 2008). We used the existing university learning management system, in our case Blackboard. In addition to the native tools available through Blackboard, several technologies were considered to support the student experience of the course, including an active learning application and the use of independent ePortfolio platforms. Students had been given the option of selecting a tool of their own choice to build an ePortfolio as a central repository of their work in previous courses, however this presented challenges in terms of consistency, continuity of access and technical support. We decided to trial a specific platform as a central repository for student work, exercises, and assessment that would then support students in building an ePortfolio across their degree studies. PebblePad was presented as a potential solution by the learning support team within the university, and trialled with students.

\section{Results: Blended Learning - Human Computer Interaction}

\subsection{Course Structure}

As a first-year course for a diverse student cohort, $\mathrm{HCl}$ required a clear course structure to support student acquisition of core concepts. Based on the lessons learned from the Project Management redesign project, a structured, module-based approach supported by an extensive course site on Blackboard was selected. This included a weekly course schedule with workshop and module links, assessment milestones, and weekly module material clearly presented. Exercises were developed in conjunction with the module material to build on the theoretical material presented, and prepare students for their assessment pieces. Assessment built progressively for submission in stages, with formative feedback and an opportunity for students to revise their work based on feedback provided.

The structure of the course design and the application of the PebblePad platform was then scaffolded with templates to support student learning, hints and supporting documents, and the use of authentic tasks. The course design aimed to support student cognitive load during learning through the provision of clear cues and timely course material through the learning platform. Further support was provided through a collaborative approach to enable students to learn through working with others. The platforms were chosen to support the course focus on the early development and progressive support of employability skills. The following sections will explore the application of these aspects.

\subsection{Scaffolding Student Learning}

As has been described, the student cohort for $\mathrm{HCl}$ is diverse and a single common level of understanding on the part of the students is lacking. Appropriately scaffolded learning assists in bridging the gap between potentially divergent starting points of comprehension and the instructors' desired state of comprehension for students (Puntambekar \& Hubscher, 2005). Course design needed to support the student's Zone of Proximal Development (ZPD): the point between "actual developmental level as determined by independent problem solving and the higher level of potential development as determined through problem solving under adult guidance and in collaboration with more capable peers" (Vygotsky, 1978, p. 86). This was supported through the development of theoretical module material, whole class discussion points, in-class team exercises, and whole-class review of exercise outcomes.

$\mathrm{HCl}$ presents topics as a series of progressive modules, providing a cohesive narrative that builds weekly. This is beneficial for the overall course structure, as it presents the opportunity to adopt a predictable weekly procedure that students can utilise to familiarise themselves with both process and content. This weekly procedure is designed to encourage preparation, stepping through theory, practical discussion and practical application. The first element is the module book, a short textbook written to summarise the theoretical content of the module, including examples of how the concepts can be implemented, or how they 
impact on situations from industry. This module book serves as the core reference point for all content delivered throughout the course. It is the foundation for the weekly lecture, which is the second component of content delivery. Each hour-long lecture serves as a dynamic summary of the weekly content and provides the first opportunity for students to clarify their understanding of the module. The lecturer is able to evaluate student understanding through micro-exercises conducted during the lecture.

Subsequent to the lecture, the students attend a two-hour seminar style workshop. Building on the structure established in the earlier project management redesign project, the workshops apply active learning techniques (Bonwell \& Eison, 1991) consisting of a large group discussion of the module content, followed by an activity to work with the theory through the application of practical tools and techniques to simple industry scenarios in small, supervised groups. This gives students the opportunity to individually clarify any uncertainty, check that their application of the concepts is correct, and ask questions about the requirements of assessment components. They then apply the tools and techniques from that module to their individual assessment.

The entire course structure is captured within the course site and presented visually to students through a master schedule linking all individual components. Through this schedule the students have access to the entire course content from week one. Students can also access their supporting technology tools through the course site, including the native Blackboard tools and PebblePad.

We used PebblePad as the collaborative platform for the weekly team workshop exercises and the development and submission point for the main individual design brief assessment. This served as a central point for students to apply techniques and concepts, and to develop a body of work demonstrating application and mastery of $\mathrm{HCl}$ theory. As a scaffolding tool it supported student application of core concepts together with reflective practice on their application (Roberts, 2018). PebblePad was set up with templates and instructions to guide students in the completion of this material.

\subsection{Templates}

The provision of templates to support student learning and application is a key element of supporting a shared understanding of the submission requirements and instructor expectations (Puntambekar \& Hubscher, 2005). As first-year students, support was required to define and guide the completion of exercises and assessments, and templates for these items provided a simple support structure. We developed a set of documents as initial templates, and then worked collaboratively with the university's learning and teaching consultants to convert these documents into PebblePad templates.

The simplest templates supported the weekly team exercises. These were structured to provide information and instructions for the exercises, and a simple point of capture for information from students. The exercises were conducted in class during the workshops, and the PebblePad platform allowed teams of students to complete the exercise within the PebblePad environment collaboratively in real time.

The most important template provided to students was the design brief that formed their individual assessment. The template consisted of ten sections, where each section corresponded to a content module. These sections were ordered to align with the delivery of content, to encourage students to spend time on their individual assessment weekly, rather than attempting to complete it all at once. This order aligns with the standard technology lifecycle process of audience research, requirement analysis, solution design, design testing, and the generation of recommendations.

The core elements of the template are based on industry documentation, including the process-driven documentation of usability evaluation and testing. However, to ensure alignment with course assessment requirements, these industry-standard components have been injected with additional requirements around theory and discussion. This includes specific discussion around the process of user-centred design and how it could have been used, and how their solution could possibly translate to different domains and usage 
contexts. Even in sections that are industry focused, such as the description of the target audience, students are asked to discuss relevant human factors and impacts, to demonstrate their understanding of more theoretical course content.

\subsection{Hints and Supporting Documents}

Every section of the assignment template on PebblePad included a collection of subsections, each with its own short hint and answer field to guide students' focus and responses. The hint could be a short collection of questions the student should seek to answer, or a recommendation of steps the student should follow to satisfy the requirements of that area. This supporting information often mirrored the assessment criteria, pointing the student towards responses that would address the criteria directly. The answer field was also designed to be intuitive for students, utilising pre-formatted tables, media fields, and text boxes to indicate the type and size of content that was expected for a given section. This breakdown of tasks into subsections lent itself to incorporation in students' PebblePad ePortfolios, as they were able to cherry pick individual sections or responses to summarise their interests and abilities, rather than having to include the entire assignment as a sample of work.

Although we designed the PebblePad templates to be intuitive, there always will be opportunities for students to misinterpret task descriptions or requirements. Students could invest time and effort into activities that do not satisfy the marking criteria, meaning that their marks reflect their misunderstanding of the instructions rather than understanding of the course content. To reduce the risk of these misunderstandings, we introduced a number of support mechanisms which clarified the purpose of the assessment, and our expectations surrounding quality, and direction.

The first mechanism was the inclusion of hints within the PebblePad templates for both the weekly exercises and the assignment, as described previously. These hints were structured to pre-empt students' incorrect assumptions of particular tasks by presenting guiding descriptions and questions. These hints also tied directly into the second support mechanism, which was the provision of the marking criteria and rubric.

A marking criteria and rubric was provided to students as a clear way to manage expectations around required work and marks for both the workshop exercises and the assignment. The marking criteria lists each element the student must satisfy within each section of their assessment, and the total number of marks that criterion contributes to the total mark. The rubric provides a breakdown of the levels of achievement (fully, largely, partially, not) within each criterion, with a short statement about the work required to attain each level. Together, these two documents give students an indication of our expectations, which allows them to plan their own distribution of effort across the criteria.

\subsection{Learning with Others}

In the past we encountered issues with students in the later years of their degree lacking experience with teamwork. $\mathrm{HCl}$ presented the opportunity to introduce teamwork skills to students in their first year, including collaboration, work allocation, time management, and communication. In their first workshop, we asked the students to form small teams (four to six people) that would then be their group for all team activities, both in the weekly workshop and for completion of the assignment. This team setup, while beneficial for learning with others, also presented a number of challenges to resolve.

In the weekly workshops, teams would work together to come up with solutions for a number of activities on PebblePad that required application of theoretical content. The largest challenge for the team workshop template was ensuring that a team of students could work collaboratively in a single space. PebblePad did allow sharing of templates for teamwork, but both staff and students found the platform to be limited. In particular, students who worked with different teams from week to week (which happened for a variety of reasons) had open access to several team spaces, and so were able to view and edit responses from teams that they hadn't necessarily worked with that week. 
While PebblePad did sometimes have a detrimental impact, the students seemed to benefit from their experiences with teamwork, both positive and negative. In terms of positive experiences, students developed their ability to have open and collaborative discussions to diversify their thinking, identify skills in themselves and team members, allocate work accordingly as well as appropriately allocate time and effort to delegated tasks. On the other hand, students experienced situations including communication breakdowns, differences in opinion, differences in perceived capability and effort, and lack of attendance by team members. While these experiences present the opportunity to improve the ability to compensate for and bounce back from team-based difficulties, at the time students often find these negative situations stressful and detrimental to their overall performance. In this respect, teamwork has to be closely managed and guided by the teaching team, to ensure that students learn, rather than break down.

\subsection{Cognitive Load}

We used PebblePad to ease cognitive load in learning for students, both at an individual level and at a collaborative learning level (Kirschner, Sweller, Kirschner, \& Zambrano, 2018). At an individual level, we used PebblePad to provide environmental triggers to support information processing and transfer (Sweller \& Sweller, 2006) through the structure, format, and prompts provided in the templates. At a collaborative learning level, we used PebblePad to provide a mediated environment for collaborative student work where students shared the learning load to reach an exercise goal (Teasley \& Roschelle, 1993). Extraneous cognitive load generated by the collaborative effort is mitigated through the use of structured templates through PebblePad, supported by clear hints and instructions.

During first year, students are learning not just material related to their courses, but how to manage university more generally and the academic expectations that exist. As a first-year course, our aim is to support the administrative process and ease the general academic cognitive load, allowing students to focus on the course material itself. This was supported through the repeated structure of module material and approach.

The modular course design set clear expectations of student progression through the course itself, and the nature of the templates provided through PebblePad supported academic expectations. We encountered some issues in this area however, as the structured nature of the entry fields within the PebblePad interface themselves led to some confusion. The entry fields appeared as text boxes, and it was not immediately apparent that the windows could be resized, or that they would automatically expand as a student wrote more text. Some students then assumed that they only needed to write a small amount for a given entry, sufficient to fill the displayed field, but no larger.

\subsection{Employability}

Information technology is a fundamentally practical discipline, and course material should facilitate the acquisition of skills that will support student employability as they progress through their study. Within $\mathrm{HCl}$, we introduce students to a set of theoretical frameworks that support the field as a discipline, and to a broader set of tools and techniques that they will use as industry professionals. The workshop exercises and the individual assignment provide students with the opportunity to apply these tools and techniques, first with supervision and support, and then independently.

The PebblePad platform provided a single point of reference for students to complete and capture their work in a forum that will persist across their academic career, and still be available after they graduate. While not required within the course itself, we encouraged the students to build an ePortfolio within PebblePad that was separate from their actual course work, and to capture example material from their assessment within their ePortfolio. This gave them the opportunity to both showcase specific skills and task completion, and to also demonstrate reflection on the process and what they had learned. 


\subsection{Authentic Tasks}

The key component of the $\mathrm{HCl}$ course, and all courses we run, is the integration of a real world problem that needs to be solved (Baldwin \& Rosier, 2017). We utilise a context that is not a fabricated project, but a new and unique business problem from a real client that we seek out every year. The chosen context then serves as not only the core scenario for the assignment, but also as a discussion topic for the weekly exercises. It can be challenging to find projects that are suitable, but feedback has shown the use of a real project as a core element of the course has a number of benefits.

The real context makes the connection between theory, practice, and real-world implementation of skills much more obvious for students. It has become a common theme that students will refuse to engage with content that isn't directly relatable to a real-world scenario, instead only placing academic value on those topics that they can clearly see as a practical and/or employable skill. This approach, both in the design context, and the format of the assessment, reinforced that every topic covered is relevant to the real world (Kolb \& Kolb, 2005). Student feedback has shown that they felt more invested in the outcomes of their assignment, as the real context introduced not only practicality, but a sense of responsibility for the quality of their outputs.

We also offer the opportunity for the best final assignments to be passed back to the client for review as proposed solutions to their business problem. For some students, the offer of having their work passed on to the actual client, with the potential to have some work that they have completed be turned into a tangible solution that people are using, is a positive motivator. This potential reward encourages them to not only extend themselves to complete the best work they can, but also propose innovative solutions to problems.

\subsection{Evaluation}

One of the core aspects of the $\mathrm{HCl}$ course is the concept of usability: the idea that people can easily apply a technological application to achieve their goal, and that the technology will be useful to the people who will use it. It is therefore critical that the course design of the $\mathrm{HCl}$ course itself supports the usability concept. Two of the approaches that are taught within the course are User Centred Design, and formal evaluation and testing, and the approach used to evaluate and improve the $\mathrm{HCl}$ course are practical applications of these techniques. The students themselves are actively involved in the process as contributors to course improvement, and the evaluation process itself is then linked back to the students as a tangible outcome. All revisions to the course design are based on feedback from students, and findings from the formal course evaluation process.

During each module workshop, instructors conduct a review session to identify any sticking points within the course material or the course structure. Students are often hesitant to participate in this process initially, however, as they see their feedback applied and as they learn more about the techniques and the $\mathrm{HCl}$ approach, participation becomes more active. This then allows group brainstorming sessions with students to identify potential solutions to any issues as they arise. This informal process also serves to support relationship building with students enabling them to feel more comfortable in approaching the teaching team with any concerns or recommendations.

At the mid-point of the teaching period an internal anonymous feedback survey is conducted by the teaching team to elicit feedback on positive and negative aspects of the course. Small changes to the course design may be initiated as a result of this feedback. Responses to all common feedback trends are delivered back to the students a few weeks later in a "closing the loop" activity (Shah, Cheng, \& Fitzgerald, 2017). At the end of each teaching period, a formal evaluation survey is conducted by the university, and students are actively encouraged to complete this to support the ongoing review process. The teaching team subsequently consult external university instructors for a peer review process, to discuss trends within content delivery and student understanding across the school. 


\section{Discussion}

\subsection{Issues and Improvements}

Student feedback in evaluations, in-class feedback sessions, and learning journal entries indicate that the module and workshop structure are successful in supporting student learning of complex material. The quality of student work generally improved across the teaching period as students work with the structure, resulting in high quality work in the final assessment piece, demonstrating student learning.

Student feedback identified a range of strengths in the course design, including the structure and presentation of the course site, the module-based course structure, module resources such as the module books and supporting resources, the format and interactivity of the class work, and the hands-on acquisition and application of skills.

Our focus in the course design review process has been to work with the issues that students have reported, and the problems we've encountered through delivery. We found that student group work for primary assessment at a first-year level is not successful and can be detrimental for some students. This has led to a shifted emphasis on small informal group work in class and individual work for major assessment, allowing students to familiarise themselves with the challenges of working in teams while still taking responsibility for their own individual work and progress.

After the first offering of $\mathrm{HCl}$ in 2016 we changed the order of the course content topics. Originally, we had introduced theoretical frameworks within the first few weeks of teaching, however for first-year students we found that this caused them to disengage with content that they considered 'heavy theory', and it was consequently more difficult to engage them with the more interactive design aspects of following modules. These in-depth theoretical frameworks are now discussed at the end of the course, and the first few weeks have proven to be integral to establishing and maintaining student engagement. We have then found that students engage more readily with the frameworks at the end of the course, with a solid foundation of practical knowledge acquired.

While the course content was described as interesting by the students, overlaps of content and assessment with other core first-year courses were identified. This led to the removal of the ePortfolio as an assessed component as it is assessed in another course, and a refined focus on potential content and depth of material that could be included in an ePortfolio. Course topics have also been reviewed to ensure originality for students.

We encountered problems with our most recent cohort in relation to their level of interaction with content and preparation for classes prior to face-to-face contact. In 2018, we introduced a formative weekly quiz that students must complete prior to workshops, with questions sourced directly from module books and course resources to incentivise engagement. This demonstrated some success, with many students acknowledging that they are now better prepared for classes and are subsequently gaining more benefits from participation. It is hoped that this will also support fundamental study skills that will be an ongoing benefit, however at this point it is too early to measure an ongoing effect to other courses as this cohort is yet to start their second year of study.

Using PebblePad for workshop exercises and the primary design brief facilitated student ability to integrate work examples into a demonstration of employable skills through their ePortfolio. Using the same platform for both course work and the ePortfolio simplified the process for students to collect their work to share with prospective employers.

While the PebblePad platform provided many benefits to students, technical issues that were experienced with the platform have also impeded student benefits and in some aspects have hindered the flow of the course design. Many students cited difficulties with their ability to format or reformat assessment material, both textual and graphic, and stated that the set formats available for submitting content limited their options and ability to present their work and showcase their skills: "there are restrictions on how the assignment can be presented, for example number of photos I could put up to represent my ideas and the consistency of font 
or layout sometimes are compromised". Students requested "better more comprehensive text editor options, that [sic] would be great." Students are familiar with more traditional text editing software, and at this stage find PebblePad's formatting options restrictive, reflecting findings from other studies where students routinely complete their work in a different text editor and then copy the material into PebblePad (Roberts, 2018). As discussed earlier, we also found that some students misunderstood the requirements for content, and provided material of limited length, depth and detail based on the physical screen size of the text input boxes.

Students enjoyed the collaborative aspects of completing their small group workshop exercises using PebblePad as a central platform, however they did find the collaborative features of the platform were highly limited. Students requested an extension of the platform to better support sharing and collaboration. They strongly endorsed the use of a central collaborative space, and requested a platform that was more flexible and robust to support this.

We were also surprised to observe, and have confirmed in student evaluations, a tendency of students to produce more informal work when submitting material through PebblePad. The formality of language used in written material, depth of analysis, and fidelity of graphics were more casual for work submitted through the PebblePad platform than students normally submit for document-based assessment. Student comments supported this, with students stating that the platform caused them to "trivialise the assessment", and to feel like the assessment was a "low-importance homework activity". These problems specifically have led us to transition back to a traditional document-based assignment template for flexibility and formality.

\section{Looking Forward}

We have identified a need to further extend guidance around the assessment requirements for the major individual design brief. We will be introducing additional structure within the assignment template to manage expectations around the amount and quality of work required, and how different information should be presented.

We use activities and responses within lectures to foster engagement with the material, understanding of relevance, and retention of the theory. While this process is effective for student learning, it is difficult to reach or engage with all students, and we will expand the current process to incorporate digital responses to questions and surveys with improved ability for the students to capture their own learning locally. Potential platforms to support these activities are the university native polling tool jPoll, the PebblePad platform, and the Echo360 Active Learning platform.

We are exploring the option of producing shorter, practical 'how-to' guides for key tools and techniques taught throughout the course, as both a support system for completing assessment and potentially a reference resource for other points in the degree. This process proved effective within the Project Management course, and would be a suitable extension to the $\mathrm{HCl}$ material. In addition, we will revisit the tools and techniques that we employ to ensure content is provided to support application in emerging technologies, such as prototyping for Virtual Reality, and evaluation and testing of Augmented Reality.

The process of review and revision of the $\mathrm{HCl}$ course is ongoing, changing with each new student cohort and with evolving industry practices. The foundation course design that we have implemented of a module-based course structure, scaffolding student learning from theory through to assessment, has provided us with a flexible base that supports this ongoing review and revision cycle. This base then allows us to trial different tools such as PebblePad to support engagement and student outcomes. These tools can support students to capture theory that they are learning in class, techniques that they are trying, observations that they have made and aspects that they have learned about their own journey. Our role as educators is to design courses and provide tools that enable this process in a manner that suits our students and their changing needs. 


\section{References}

Baldwin, C., \& Rosier, J. (2017). Growing future planners: A framework for integrating experiential learning into tertiary planning programs. Journal of Planning Education and Research, 37(1), 43-55. doi.org/10.1177/0739456X16634864.

Bonwell, C. C., \& Eison, J. A. (1991). Active learning: Creating excitement in the classroom. School of Education and Human Development, George Washington University. https://eric.ed.gov/?id=ED336049. Accessed

Cook-Sather, A., Bovill, C., \& Felten, P. (2014). Engaging students as partners in learning and teaching: A guide for faculty. San Francisco: Jossey Bass.

Felten, P., Bovill, C., \& Cook-Sather, A. (2014). Engaging students as partners in learning and teaching (1): Benefits and challenges - what do we know? In International Conference on Education Development.

Freeman, S., Eddy, S. L., McDonough, M., Smith, M. K., Okoroafor, N., Jordt, H., \& Wenderoth, M. P. (2014). Active learning increases student performance in science, engineering, and mathematics. Proceedings of the National Academy of Sciences of the United States of America, 111 (23), 8410-5. http://doi.org/10.1073/pnas.1319030111.

Garrison, D. R., \& Vaughan, N. D. (2008). Blended learning in higher education: Framework, principles, and guidelines. Hoboken: John Wiley \& Sons.

Kennedy, T. J., \& Odell, M. R. L. (2014). Engaging students in STEM education. Science Education International, 25(3), 246-258.

Kirschner, P. A., Sweller, J., Kirschner, F., \& Zambrano R., J. (2018). From cognitive load theory to collaborative cognitive load theory. International Journal of Computer-Supported Collaborative Learning, 13(2), 213-233. http://doi.org/10.1007/s1 1412-018-9277-y.

Kolb, A. Y., \& Kolb, D. A. (2005). Learning styles and learning spaces: Enhancing experiential learning in higher education. Academy of Management Learning \& Education, 4(2), 193-212. http://doi.org/10.5465/AMLE.2005.17268566.

Koper, R. (2005). An introduction to learning design. In R. Koper \& C. Tattersall (Eds.), Learning Design: A Handbook on Modelling and Delivering Networked Education and Training (pp. 3-20). Berlin/Heidelberg: Springer-Verlag. http://doi.org/10.1007/3-540-27360-3_1.

Moreton, E. O., \& Conklin, J. L. (2015). Closing the loop on nursing library instruction: Using student performance to improve outcomes. Medical Reference Services Quarterly, 34(1), 113-121. http://doi.org/10.1080/02763869.2015.986805.

Potter, L. E. (2018). A day in the life: An interactive application to introduce IT students to the workplace. In Proceedings of the 2018 ACM SIGMIS Conference on Computers and People Research, 138-142. http://doi.org/10.1145/3209626.3209716.

Puntambekar, S., \& Hubscher, R. (2005). Tools for scaffolding students in a complex learning environment: What have we gained and what have we missed? Educational Psychologist, 40(1), 1-12. http://doi.org/10.1207/s15326985ep4001_l.

Roberts, P. (2018). Developing reflection through an ePortfolio-based learning environment: design principles for further implementation. Technology, Pedagogy and Education, 27(3), 313-326. http://doi.org/10.1080/1475939X.2018.1447989.

Shah, M., Cheng, M., \& Fitzgerald, R. (2017). Closing the loop on student feedback: The case of Australian and Scottish universities. Higher Education, 74(1), 115-129. http://doi.org/10.1007/s10734-016-0032-x.

Shaidullin, R. N., Safiullin, L. N., Gafurov, I. R., \& Safiullin, N. Z. (2014). Blended Learning: Leading Modern Educational Technologies. Procedia - Social and Behavioral Sciences, 131 (904), 105-110. http://doi.org/10.1016/j.sbspro.2014.04.087.

Simonsen, J., \& Robertson, T. (2013). Routledge International Handbook of Participatory Design. Taylor \& Francis. 
Sweller, J., \& Sweller, S. (2006). Natural Information Processing Systems. Evolutionary Psychology, 4(1), 147470490600400. http://doi.org/10.1177/147470490600400135.

Teasley, S., \& Roschelle, J. (1993). Constructing a joint problem space: The computer as a tool for sharing knowledge. In S. P. Lajoie \& S. J. Derry (Eds.), Computers as cognitive tools (pp. 229-258). L. Erlbaum Associates.

The Joint Task Force on Computing Curricula. (2013). Computer Science Curricula. Association for Computing Machinery (ACM) \& IEEE Computer Society. http://doi.org/10.1145/2534860.

Topi, H., Valacich, J. S., Wright, R. T., Kaiser, K. M., Nunamaker, J. F., Sipior, J. C., \& de Vreede, G. J. (2010). Curriculum Guidelines for Undergraduate Degree programs in Information Systems. https://dl.acm.org/citation.cfm?id=2593310. Accessed 26 November 2018.

Vygotsky, L. S. (1978). Mind in Society: The development of higher psychological processes. Cambridge, MA: Harvard University Press.

Wang, Y., Han, X., \& Yang, J. (2015). Revisiting the blended learning literature: Using a complex adaptive systems framework. International Forum of Educational Technology \& Society, 18(2), 380-393. 